\title{
Employment of counsellors and mental health professionals by fundholding general practices
}

\author{
T. I. R. Mutale
}

\begin{abstract}
Recent surveys have shown that general practitioners have begun to employ proctice counsellors. The recent establishment of fundholding practices has made it possible for general practtioners (GPS) to be direct purchasers of health services. The number and nature of counsellors and specialist mental health professionals directly employed by fundholding practices is reported.
\end{abstract}

The introduction of fundholding practices has given general practitioners (GPs) direct control over some secondary care services and increased their influence on health care planning. GPs can now ensure that the pattern of services reflects the needs of their patients (Roland, 1991). One such need is the care of people with mental health problems who form up to $40 \%$ of primary care attenders (Goldberg \& Huxley, 1992). Thus it is not surprising that there is a growing demand for counsellors at primary care level (Sibbald et al, 1993).

Most previous studies have looked at professionals employed by practices primarily to provide counselling (Sibbald et al, 1993; Corney, 1990) rather than at a broad range of mental health professionals such as psychiatrists, psychologists, family therapists, art therapists, drama therapists, psychotherapists or play therapists. One of the few surveys to include a broad range of mental health professionals concentrated on nonspecific links with practices and did not consider the direct employment of individual professionals (Thomas \& Corney, 1992). Furthermore, no previous study has determined the number and nature of child mental health professionals directly employed by general practices reported on the direct purchasing of services from individual mental health professionals by fundholding practices.
This study determined the nature and number of counsellors and a broad range of specialist adult and child mental health professionals directly employed by fundholding practices. The definition of counsellor is problematic (Newman, 1990). In this study a counsellor was defined as any professional, who, in the view of the GP, had been employed primarily to provide counselling. Specialist professionals were defined as any professional who provided specialised input, such as art, play, family and drama therapy, or had specialist qualifications, for example psychiatrists, psychologists, psychotherapists and all child professionals. However, professionals with specialist qualifications who, in the opinion of the GP, had been employed primarily to provide counselling were classified as counsellors rather than specialists.

The General Medical Services Committee (GMSC) has now withdrawn its opposition to fundholding, and in April 1994 40\% of GPs became fundholders (Smith, 1993). The direct employment of mental health staff by fundholders is therefore likely to have important financial and service implications for secondary care mental health units.

\section{The study}

During May and June 1993, 300 general practices were chosen from a list of first and second wave fundholding practices (Institute of Health Services Management, 1993), using a random numbers table (Daniel, 1991). One GP was chosen from each of the 300 index practices using a random numbers table. Each of the 300 GPs was sent a questionnaire together with a personally 
Table 1. Counsellors and specialist mental health professionals from 210 general practices. Numbers refer to professionals (\%)

\begin{tabular}{lc}
\hline Profession & $\begin{array}{c}\text { Number directly } \\
\text { employed (\%) }\end{array}$ \\
\hline Adult counsellors & $112(49.3)$ \\
Adult psychologists & $27(11.9)$ \\
Adult psychotherapists & $20(8.8)$ \\
Child psychologists & $13(5.7)$ \\
Child psychiatrists & $13(5.7)$ \\
Family or marital therapists & $10(4.4)$ \\
Child psychotherapists & $10(4.4)$ \\
Child or youth counsellors & $6(2.6)$ \\
Drama therapists & $4(1.8)$ \\
Play therapists & $4(1.8)$ \\
Adult psychiatrists & $3(1.3)$ \\
Art therapists & $3(1.3)$ \\
Community psychiatric nurses & $2(0.9)$ \\
Total number employed & $227(100)$ \\
\hline
\end{tabular}

addressed covering letter. GPs who had not responded within three weeks were sent another questionnaire.

The questionnaire asked GPs to indicate by a tick if they directly employed any of the professionals listed in Table 1 , and to note down the qualifications of each professional they employed. A space was left for the addition of types of professionals not on the list.

A separate section required respondents to indicate by a tick if their practice had any of the following links with a psychiatrist, psychologist or community psychiatric nurse (CPN): professional held regular practice based clinics, but did not discuss cases with GPs; professional held regular practice-based meetings with GPs; or professional and GP assessed patients together. The purpose of this section was to determine the extent of links between fundholders and secondary care level professionals.

\section{Findings}

Out of 300 GPs, $210(70 \%)$ returned completed questionnaires. Table 1 shows the number of counsellors and specialist mental health professionals directly employed by fundholding practices. Of the 210 practices, $128(61 \%)$ employed at least one counsellor or a specialist mental health professional, and 13 (6\%) employed at least three mental health professionals. Of the 227 professionals, 56
Table 2. Qualifications of 112 adult counsellors directly employed by 210 general practices. Numbers refer to counsellors (\%)

\begin{tabular}{|c|c|}
\hline Quallification & $\begin{array}{l}\text { Number directly } \\
\text { employed (\%) }\end{array}$ \\
\hline Not known to GP & $57(50.9)$ \\
\hline counselling certificate & $13(11.6)$ \\
\hline Trained by Relate & $8(7.1)$ \\
\hline $\begin{array}{l}\text { Approved by British Association of } \\
\text { Counselling }\end{array}$ & $8(7.1)$ \\
\hline CPN plus counselling certificate & $8(7.1)$ \\
\hline RGN plus counselling certificate & $4(3.6)$ \\
\hline CPN, no counselling centificate & $3(2.7)$ \\
\hline Trainee counsellors & $3(2.7)$ \\
\hline RGN plus Aromatherapy training & $1(0.9)$ \\
\hline Psychology degree only & $1(0.9)$ \\
\hline $\begin{array}{l}\text { Psychology degree plus counselling } \\
\text { certificate }\end{array}$ & $1(0.9)$ \\
\hline MA degree only & $1(0.9)$ \\
\hline Training in relaxation techniques & $1(0.9)$ \\
\hline Trained alcohol counsellor & $1(0.9)$ \\
\hline $\begin{array}{l}\text { Social worker plus counselling } \\
\text { certificate }\end{array}$ & $1(0.9)$ \\
\hline $\begin{array}{l}\text { Social worker plus training } \\
\text { in behavioural therapy }\end{array}$ & $1(0.9)$ \\
\hline $\begin{array}{l}\text { Total number of adult counsellors } \\
\text { employed }\end{array}$ & $112(100)$ \\
\hline
\end{tabular}

(25\%) were employed to work with children or families. One practice employed a private clinic (two CPNs) and a psychiatrist) to manage mental health problems. The practice paid a fee for each patient they sent to the private clinic.

Table 2 shows the qualifications of the 112 adult mental health professionals employed primarily to provide counselling for adults. Of the 210 practices, 102 (49\%) directly employed adult counsellors. Of the 112 adult counsellors, 47 (42\%) had counselling qualifications known to GPs. Five practices did not have to pay for the services of a counsellor; three had trainee counsellors; one had a counsellor provided by a voluntary body; and one arranged for patients to pay their own fees.

Of the 210 practices, 69 (33\%) employed adult counsellors only, 26 (12\%) specialist mental health professionals only, and 33 (16\%) an adult counsellor as well as a specialist mental health professional.

Practices which employed specialist mental health professionals were not significantly more likely to employ adult counsellors than 
practices who did not (33 out of 59 (56\%) v. 69 out of $151(46 \%)$, d.f. $\left.=1, \chi^{2}=1.394, P=0.24\right)$. Practices which had links with a psychiatrist, psychologist or CPN (secondary care services) were significantly more likely to employ adult counsellors than those had no such links (92 out of $161(57 \%)$ v. 10 out of $49(20 \%)$; d.f.=1, $\left.\chi^{2}=18.850, P<0.0001\right)$.

Of the 210 practices, 30 (14\%) had CPNs who were available to provide counselling. But these CPNs were not directly employed by the practices, and were not included in the analysis.

\section{Comment}

This study demonstrates that fundholding practices purchase services directly from both individual specialist mental health professionals and counsellors. The demand for more specialist psychological input, in addition to counselling, is probably a reflection of the closure of mental hospitals and the shifting of mental health care into the community (Goldberg \& Jackson, 1992).

An interesting finding was that practices which had formed links with a psychiatrist, psychologist or CPN were also more likely to employ an adult counsellor. This is consistent with the findings of a recent survey (Thomas \& Corney, 1992). It was striking that the employment of a specialist mental health professional did not affect the probability of a practice employing an adult counsellor as well. This suggests that adult counsellors were employed in addition to, rather than instead of, specialist mental health staff.

An important finding was that the profile of professionals directly employed included both child and adult practitioners, an indication that the demand for psychological help comes from all age groups.

The profile of professionals employed primarily as adult counsellors was similar to that demonstrated by Sibbald et al (1993). However, in contrast to Sibbald's study, only two psychologists were employed as counsellors while the majority were employed in a specialist capacity. It is worrying that GPs did not know the qualifications of $51 \%$ (57 out of 112) of the adult counsellors they employed. It is the responsibility of the GP to ensure that professional health staff employed by their practice are properly qualified (Newman, 1990). However, when all mental health staff are considered together, the proportion whose qualifications were not known to the GP fell to $25 \%$ (57 out of 227).

The employment of specialist mental health staff is important because they compete directly with the specialist secondary care units. A good example is the practice that directly employed a private clinic (two CPNs and a psychiatrist) to assess and treat patients on their list. This arrangement indicates one possible future pattern of community mental health services, particularly as the number of fundholders rises.

The number of practices who employed adult counsellors (49\%) was higher than that reported in previous studies (Sibbald et al, 1993 [31\%]; Thomas \& Corney, 1992 [17\%]). When both counsellors and specialist mental health professionals were included, the percentage of practices that employed a mental health professional was $61 \%$. Clearly, the percentage of fundholding practices that employed mental health professionals was well above the national average. These findings suggest that fundholders use their direct purchasing power to ensure that both counselling and specialist psychological help are available and accessible to their patients.

In conclusion, the increase in the number of fundholding GPs to 40\% (April 1994) will probably have a significant impact on the delivery of both adult and child mental health services. Specialist secondary care services ignore fundholding practices at their peril (Puetz, 1993).

\section{References}

CORNEY, R. H. (1990) Counselling in general practice - does it work? Discussion paper. Journal of the Royal Society of Medicine, 83, 253-257.

GolDBERG, D. \& HUXIEY, P. (1992) Common Mental Disorders: a Biosocial Model. London: Routledge.

DANIEL, W. W. (1991) Statistical tables. In Biostatistics: a Foundation for Analysis in the Health Sciences. Middlesex: John Wiley \& Sons.

GolDBERG, D. \& JACKSON, G. (1992) Interface between primary care and specialist mental health care. British Journal of General Practice, 42, 267-268.

INSTITUTE OF HEALTH SERVICES MANAGEMENT (1993) General practice fundholders. In The Hospital and Health Services Year Book. London: Institute of Health Services Management.

National Health SERVICE MaNagement (1992) Integrating Primary and Secondary Health Care. London: NHS Management Executive.

NewMAN, C. V. (1990) Advice on the appointment of psychologists and counsellors within general practices. British Journal of General Practitioners, 40, 388-389. 
PUETZ, M. (1993) Counselling in primary care? Expectations, values and effectiveness. Psychiatric Bulletin. 17. 169.

Roland, M. (1991) Fundholding and cash limits in primary care: blight or blessing. British Medical Journal, 303. 171-172

Sibbald, B., Addington-Hall, J., Brenneman, D. \& Freeling, P. (1993) Counsellors in English and Welsh general practices: their nature and distribution. British Medical Journal, 306, 29-33.

SMITH, J. (1993) GPs in Britain withdraw opposition to fundholding. British Medical Journal, 306. 1713.
THOMAS, R V. R \& CORNEY, R H (1992) A survey of links between mental health professionals and general practices in six district health authorities. British Journal of General Practice, 42, 358-361.

T. I. R. Mutale, Senior Registrar in Child and Adolescent Psychiatry, Department of Psychological Medicine, Great Ormond Street Hospital Trust, Great Ormond Street, London WC1 3JH

\section{Caring for a Community}

\section{The Community Care Policy of the Royal College of Psychiatrists}

\section{by Dinesh Bhugra, Keith Bridges and Chris Thompson}

This report presents some examples of philosophy, approaches, good practices, and service aspirations found in the UK. Some of these services have resulted from Government policy and research into specific psychiatric disorders while others have drawn upon developments abroad. Many services, however, have developed based on clinical experiences, pragmatism, a sensitivity to local needs, collaborative approaches involving a variety of local organisations, and the desire of practitioners to have available to the public an effective range of services. The report describes actual and potential community services providing for the mental health needs of the severely mentally ill.

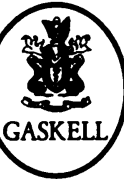

\section{$\bullet £ 10.00 \bullet 90 p p . \bullet 1995 \bullet$ ISBN $090224177 \mathrm{X}$}

Available from bookshops and from the Publications Department, Royal College of Psychiatrists, 17 Belgrave Square, London SW1X 8PG (Tel. 0171-235 2351 extension 146) 